\title{
Primary B cell malignant lymphoma of the trachea
}

\author{
J WIGGINS, E SHEFFIELD, MALCOLM GREEN
}

\author{
From the Brompton Hospital, London
}

\begin{abstract}
A case of primary B cell lymphoma of the trachea is reported. It is suggested that it is an example of a tumour of mucosa associated lymphoid tissue, or "maltoma."
\end{abstract}

Primary malignant tumours of the trachea ${ }^{1}$ are uncommon, are often extensive at presentation, and frequently give rise to symptoms of upper airway obstruction. ${ }^{2}$ Although most are squamous carcinomas, various other neoplasms have been described. Primary lymphomas arising at this site are exceedingly rare, but they may be associated with a relatively favourable prognosis.

\section{Case report}

A 63 year old Greek man with a smoking history of 80 pack years presented with cough and wheeze of six months' duration. He was treated for asthma initially, but inhaled bronchodilators and corticosteroids were not helpful. Fibreoptic bronchoscopy in Greece showed a polypoid lower tracheal lesion, and he was referred to the Brompton Hospital for further management.

Apart from his respiratory symptoms he felt well. There had been no chest pain, weight loss, night sweats, or haemoptysis. On examination he was very dyspnoeic, with inspiratory and expiratory stridor; there was no clubbing, lymphadenopathy, or hepatosplenomegaly. A chest radiograph, electrocardiogram, full blood count, serum biochemistry, and erythrocyte sedimentation rate were all normal, and no malignant cells were found in the sputum. The FEV , was 0.8 (predicted 2.55) 1 , forced vital capacity (FVC) 1.8 (predicted 3.55) 1 , and peak flow (PEF) 180 (predicted 498) $1 / \mathrm{min}$, with a flat upstroke to the spirometric trace of volume against time.

Rigid bronchoscopy showed the distal $6.5 \mathrm{~cm}$ of the trachea to be encircled by a fleshy, polypoid tumour, which extended to the carina. The proximal trachea was normal. Biopsy specimens were taken and a large amount of tumour was resected by means of diathermy. After bronchoscopy the patient's stridor was relieved and his dyspnoea was greatly improved. The FEV, had increased to 2.551 , FVC to 3.41 , and PEF to $265 \mathrm{l} / \mathrm{min}$.

Histologically, the subepithelial tissue of the trachea was infiltrated by neoplastic centrocytic and centroblastic cells (figure), and these cells infiltrated the overlying respiratory epithelium. Immunocytochemical examination confirmed that the tumour was a $B$ cell centroblastic-centrocytic

Address for correspondence: Dr John Wiggins, Brompton Hospital, London, SW3 6HP.

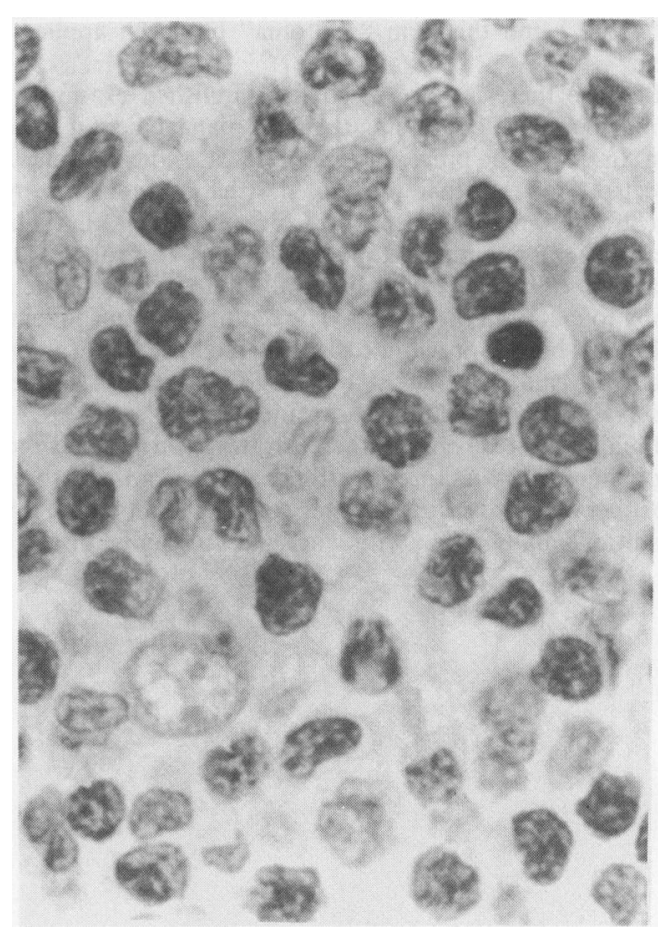

Fig Sections of tracheal biopsy showing a malignant lymphoma composed of a monomorphic population of atypical malignant lymphocytes. (Haematoxylin and eosin.)

lymphoma. Peripheral lymphocyte markers were not investigated.

Staging investigations, including thoracic and abdominal computed tomography and bone marrow aspiration, showed no abnormality, and because the lesion appeared to be localised fractionated local radiotherapy was recommended. The patient elected to return to Greece for treatment and, although he has since defaulted from follow up, he is currently well.

\section{Discussion}

Primary extranodal lymphomas comprise about $10 \%$ of all malignant lymphomas. ${ }^{3}$ Almost any organ may be affected, although most arise in the gastrointestinal tract. ${ }^{4}$ Primary tracheal lymphomas are extremely rare: only two other cases have been reported in English language publications. ${ }^{5} 6$

The present case has several features in common with 
previously reported cases. The lesion was polypoid and circled the lower trachea. There was no evidence of metastases despite extensive local disease, and there were no systemic or "B" symptoms. These features suggest that this type of tumour behaves differently from other lymphomas. Indeed, primary extranodal lymphomas seem to be associated with a good prognosis, ${ }^{3}$ and when metastases occur they may affect unusual sites. ${ }^{7}$ Probably primary extranodal lymphomas, including lesions of the trachea, originate in mucosa associated lymphoid tissue or "MALT," and the term "maltoma" has been applied to them. ${ }^{7}$

Because there are as yet so few published examples of primary tracheal lymphoma the ideal management is uncertain. In one of the previously reported cases the tumour was resected, ${ }^{6}$ and the other was treated with local radiotherapy. ${ }^{5}$ Local radiotherapy was planned for our patient, and when there are no identifiable metastases this is probably the treatment of choice, together with "debulking" at bronchoscopy to maintain the airway. The outlook for our patient is unknown, but the previous cases were recurrence free at two ${ }^{5}$ and five ${ }^{6}$ years after presentation. A good prognosis has been observed with other primary extranodal lymphomas. ${ }^{3}$

Finally, this case once again illustrates the trap of diagnosing upper airway lesions as asthma, a problem that arose in the other reported cases of primary tracheal lymphoma. Both conditions may present with wheezing but can be distingui- shed by differences in the shape of the flow-volume loop. I asthma the expiratory phase shows volume dependent airwa collapse, but in upper airway lesions there is blunting of the peaks of either the inspiratory or the expiratory loop? depending on the site of the lesion. ${ }^{2}$

\section{References}

I McCafferty GJ, Parker LS, Suggit SC. Primary malignant disease of the trachea. $J$ Laryngol Otol 1964;78:441-79.

2 Harrison BDW. Upper airway obstruction - a report on sixteen patients. $Q J$ Med 1976;45:625-45.

3 Rudders RA, Ross ME, Delellis RA. Primary extranoda lymphoma. Response to treatment and factors influencingu prognosis. Cancer 1978;42:406-16.

4 Moore I, Wright DH. Primary gastric lymphoma-a tumour of mucosa-associated lymphoid tissue. A histological and immunohistochemical study of 36 cases. Histopatholog. 1984;8:1025-39.

5 Pradhan DJ, Rabuzzi D, Meyer JA. Primary solitary lymphoma of the trachea. J Thorac Cardiovasc Surg 1975;70:938-40.

6 Maeda M, Kotake Y, Monden Y, Nakaharu K, Kawashima Y Kitamura $H$. Primary malignant lymphoma of the trachea. $L$ Thorac Cardiovasc Surg 1981;81:835-9.

7 Mead AM, Whitehouse JMA. Modern Management of noneo Hodgkins lymphoma. Br Med J 1986;293:577-80.

8 Isaacson PG, Spencer J. Malignant lymphoma of mucosae associated lymphoid tissue. Histopathology 1987;11:445-62. 